\title{
Digital Scotland, the relevance of library research and the Glasgow Digital Library Project
}

\author{
DEREK LAW and DENNIS NICHOLSON
}

\begin{abstract}
The Glasgow Digital Library (GDL) Project has a significance over and above its primary aim of creating a joint digital library for the citizens of Glasgow. It is also both an important building block in the development of a planned and coordinated 'virtual Scotland' and a rich environment for research into issues relevant to that enterprise. Its creation comes at a time of political, social, economic and cultural change in Scotland, and may be seen, at least in part, as a response to a developing Scottish focus in these areas, a key element of which is a new socially inclusive and digitally driven educational vision and strategy based on the Scottish traditions of meritocratic education, sharing and common enterprise, and a fiercely independent approach. The initiative is based at the Centre for Digital Library Research at Strathclyde University alongside a range of other projects of relevance both to the development of a coherent virtual landscape in Scotland and to the GDL itself, a supportive environment which allows it to draw upon the research results and staff expertise of other relevant projects for use in its own development and enables its relationship to virtual Scotland to be both explored and developed more readily. Although its primary aim is the creation of content (based initially on electronic resources created by the institutions, on public domain information, and on joint purchases and digitisation initiatives) the project will also investigate relationships between regional and national collaborative collection management programmes with SCONE (Scottish Collections Network Extension project) and relationships between regional and national distributed union catalogues with CAIRNS (Cooperative Academic Information Retrieval Network for Scotland) and COSMIC (Confederation of Scottish Mini-Clumps). It will also have to tackle issues associated with the management of co-operation.
\end{abstract}

\section{Introduction}

Although the fact of setting up the Scottish Parliament is a very recent one, it was preceded by an extended period of national debate on the nature and shape of such a body and what its powers and ambitions should be. This was a broadly based debate involving a very large part of the professional and managerial polity. One clear goal which emerged was a desire to be different from the traditional factional politics of Westminster and to be democratically inclusive.

This was encapsulated in the phrase 'Digital Democracy', although little real thought was given as to how this was to be achieved. At the same time Scottish opinion formers offered their ritual genuflection to the Scottish tradition of meritocratic education. Moreover, in Scotland and in the UK generally, funding for research and development in information services remained at unusually high levels, even although running cost budgets for libraries remained depressed. Scotland is a small country of some five million people and one with a long tradition of sharing and common enterprise and of jealous independence. This is reflected in everything from the long-standing Scottish Library and Information Council (SLIC - see http://www.slainte.org.uk/Slic/slichome.htm) to the more recent Scottish Cultural Resources Access Network (SCRAN - see http://www.scran.ac.uk/). This spirit of independence also implicitly ruled out a number of alternative strategies. Leaving developments to the marketplace would provide the sort of commercially driven systems unsuited to a country with 
substantial pockets of urban deprivation and a vast rural hinterland. Leaving it to the big countries would provide services and solutions unsuited to small countries. There was also a belief that small countries such as Finland and Singapore were providing much more effective solutions than large countries. Leaving it to the publishers allowed the development of commercial systems perhaps unsuited to the dissemination of public domain and open systems. Most importantly there was a feeling that we are and will be producers and not just consumers of information and must develop systems that took account of this fact.

\section{A new vision of education and the role of government}

It is a commonplace that Scotland has always been much more socialist (in the literal sense) than most of the rest of the United Kingdom. From this derives a belief that the market is not always enough to drive socially beneficial change and that government action will be the key to encouraging such change. Scotland has also for many years looked with some wonder at the way in which small Scandinavian countries can be effective as well as simply independent in the international arena. The example of Finland has been seen as particularly relevant to the aspirations of a small first world country. The point has also been made repeatedly that much of the content, community information and teaching packages are produced by Scots and for Scots. Scottish education is militantly different from the rest of the UK, but as a small market has perforce developed much of its own teaching content for many years.

A new socially inclusive and digitally driven educational vision and strategy has begun to develop from this larger picture and has forced information specialists to reconsider their role in this larger activity. The focus is very firmly on the university or the school rather than on the library alone. Glasgow is piloting the concept of 'The Learning City'. Rather than traditional sectoral boundaries such as primary or tertiary education which encourage links vertically by sector, new clusters are being created which encourage a seamless regional approach to education. This allows potential students to interact with a single point for all their educational needs. Technology such as the Clyde Virtual University, developed for higher education in Scotland is being used to develop access to learning materials in both schools and further education. Content and its management is seen as central to that development. Quite surprisingly, for example, the Scottish Executive has been persuaded that the provision of teaching materials is not sufficient, but that good metadata is also necessary to ensure good access.

But even a small country such as Scotland is not uniform in need and public funds are used somewhat schizophrenically to support both national (i.e. Scottish) and regional initiatives. The Glasgow Digital Library is a perfect example of work which is seen both as a local resource but also as a national exemplar.

\section{The Glasgow Digital Library Project and its significance}

The Research Support Libraries Programme (RSLP) funded the cross-sectoral Glasgow Digital Library project (for further information, see http://gdl.cdlr. strath.ac.uk/) but it has a significance over and above the clear value of its primary aim of creating a joint digital library to serve the users and staff of the participating institutions (three universities, 10 further education colleges and Glasgow Public Libraries and Archives). Aiming ultimately to encompass all important digital collections for, about and in Glasgow, and to serve all of the citizens of Scotland's largest city, regardless of age or level of educational development, the initiative offers both a mechanism for bringing an initial service into being, and a rich environment for research into a range of key issues of vital 
importance to a country whose recently reconvened Parliament sees the appropriate and timely strategic application of information and communication technologies as central to the economic, educational and cultural future of its citizens. As the government's Digital Scotland initiative (for further information, see http://www.scotland.gov.uk/digitalscotland/) gathers momentum, there is an increasing focus on the local, regional and national building blocks required to bring into being key elements of the vision - one particularly important element being a coherent and co-ordinated networked system offering the Scottish people ready access to digital resources that will meet their education, research, public information and recreation needs. Since the GDL aims to bring a similar system into being to serve the Glasgow metropolitan

area, it will face many of the same issues as the national equivalent, hopefully providing illumination to both enterprises on a range of pertinent research questions and practical implementation problems:

User issues: who are the users, what are their needs in respect of content, finding tools, system interfaces, language, can they be categorised in ways that will make a user adaptive system a realisable aim?

Content issues: creation and identification, design, maintenance and preservation, description, financing, managing collaborative collection management.

Standards.

Linking users and content in a standards based distributed environment: designing the finding tools, inter-operability, navigation, integration, access, metadata, user-adaptive interfaces and information landscapes.

A management, policy and strategy framework: creating a management structure and policy framework that will allow the concept to be developed and maintained into the long-term future.

Managing co-operative relationships where an element of competition is retained.

In addition, since the GDL will itself be an important regional building block in Digital Scotland, and aims to be a model for other similar regional initiatives, it should provide a useful and relevant perspective on how the national whole relates and integrates with its regional constituents, and how in turn these two levels relate and integrate with the local constituents they are formed from. A close working relationship with other projects based at the Centre for Digital Library Research (CDLR - see http://cdlr.strath.ac.uk/) that have a bearing on these and other GDL-related issues, and with other similar projects or initiatives where there is CDLR involvement, should also be of value. These are described further in the following section. Some projects such as the BUBL gateway service, the Clyde Virtual University and the Scottish clumps project

(CAIRNS) predate the CDLR and helped provide the basis for its creation, along with other now completed projects such as CATRIONA I and II. $(1,2)$

\section{The CDLR: a supportive local environment contributing to Digital Scotland}


The original submission for RSLP ( for further information see http://www.rs/p.ac.uk/) funding to develop the Glasgow Digital Library described the proposed project in the following way:

"The Glasgow Digital Library is a city-wide initiative which aims to create a wholly digital library to support teaching, learning and research at all levels in the city. The project aims significantly to enhance existing collaboration within the City of Glasgow and to explore the potential of Clydenet (the local Metropolitan Area Network) as a delivery vehicle for content. There is already significant interchange of users between the partners (Glasgow, Glasgow Caledonian and Strathclyde Universities, the Glasgow Tele-colleges Network institutions, and Glasgow City Council Libraries and Archives) and the project will identify, create, mirror and purchase content of common interest to some or all of the partners to create a collaborative, cross-sectoral, digital collection of resources that will be of significant value, both to researchers in the

Clydenet area, and to researchers elsewhere with an interest in Glasgow-oriented or Glasgow-based research collections. The particular lessons to be learnt are expected to be in shared digital collection management within a large metropolitan area, the management, distribution and accessibility of locally created, stored or purchased resources, and in the use of the Metropolitan Area Networks(MANs) in these contexts. A key aim is to create a MANbased Digital Library service and demonstrator based on shared collections and a co-operative approach to collection development and management. This will be of value both in itself and as a model for other MANs. Integration with CAIRNS will allow inter-MAN issues to be explored. With the SCONE RSLP project also based at the Centre, useful lessons should also be learnt on the inter-relationships between MAN-based (GDL) and national (SCONE) collaborative collection management programmes. The joint digital library will be based initially on electronic resources created by the institutions, on public domain information, and on joint purchases and digitisation initiatives, but the longer-term aim will be to establish the GDL as a virtual colibrary of the majority of public institutions in Glasgow."

This makes clear the importance of relationships to two other projects managed or partially managed by the CDLR but this is only the tip of the iceberg. The Glasgow Digital Library project is one of a range of other projects and initiatives which the CDLR at Strathclyde University either manages or is closely involved with and it has a good - and often close - working relationship with the others. Set up in 1999, the Centre is managed jointly by the University's Directorate of Information Strategy and Department of Information Science and currently manages, or has a close association with a number of additional projects and initiatives as described here.

\subsection{DIO (Digital Information Office)}

The Digital Information Office is an initiative funded by the University of Strathclyde itself. It was set up partly as a response to the CATRIONA II project, which investigated questions relating to the university management of locallycreated electronic resources and focuses on issues relevant to the creation and management of electronic teaching and research resources in Strathclyde University. Responsible for both the professional management of electronic teaching and research resources created within Strathclyde and the co-ordination of University wide interest in commercially acquired electronic information resources, the DIO aims, amongst other things, to create a metadata repository 
and associated web-based service interface for the University's electronic resources and to advise on the development, maintenance and dissemination of policies and standards associated with the creation, description (metadata), storage, organisation, maintenance, security and copyright of digital information. One aim of the DIO is to play a key role in the creation of some of the content in the Glasgow Digital Library and to work with Strathclyde

University Library to create the metadata for that content. The Library cataloguing department will use OCLC's CORC (Cooperative Online Resource Catalog) service to facilitate this task and may also utilise the CORC pathfinder creator to enhance browsing in the GDL and DIO databases. The DIO also aims to work to encourage the management of locally created electronic teaching and research resources in other universities in Scotland, particularly those in the GDL group.

\subsection{The JISC Intellectual Property Rights (IPR) Study}

Based at the Strathclyde University Centre for Educational Systems, the Joint Information Systems Committee (JISC see $h t t p: / / w w w . j i s c . a c . u k /$ ) funded study on IPR aims to identify the issues and problems concerning IPR found in higher education institutions in the UK and make practical recommendations which they could reasonably be expected to implement. The focus is on copyright, particularly for material in or converted to electronic form. As such, the outcomes are likely to be of direct value to the GDL and its participants.

\subsection{GAELS (Glasgow Allied ELectronically with Strathclyde)}

GAELS aims to link a number of services between the universities of

Strathclyde and Glasgow. This includes:

- improve joint access to electronic information services and resources for postgraduate students and staff researchers in the engineering faculties at Glasgow and Strathclyde Universities;

- provide joint web-based training materials for postgraduates at the two sites;

- research problems and issues arising out of the joint provision of such services;

- ultimately extend collaborative services and training to all faculties in the two universities.

GAELS has identified the potential for significant savings to be made between the two engineering faculties, shown the potential value of the collaborative work of projects such as the GDL, and provided valuable research data on the difficulties faced by such projects and on possible solutions.

\subsection{CVU (Clyde Virtual University)}

Based at the Strathclyde University Centre for Educational Systems, and Europe's first virtual university when created in 1995, the CVU is a collaborative attempt to develop and deliver Internet-based teaching materials (together with virtual reality educational worlds, online assessment and automated marking, desktop video conferencing, and text-based discussion forums) to students at Glasgow, Strathclyde, Glasgow Caledonian and Paisley Universities and the Glasgow School of Art. The CVU can provide the GDL with experience and expertise relevant to a Glasgow-based co-operative venture and, potentially, a ready-made joint virtual university for the GDL to serve (although the fact that the groups of partners in the two projects differ slightly is an issue to resolve in this respect).

\subsection{EBONI (Electronic Books Online Interface)}


EBONI is a JISC-funded project looking at how the design features of electronic books affect information intake by users. It should provide the GDL with vital information on the design of interfaces to individual digital resources in the joint library and perhaps also on GDL interface design generally. It may also provide vital information on how users use digital resources.

\subsection{INSIGHT}

INSIGHT is a project that seeks to quantify the organisational value for money of information technology. Its findings should provide background information that will help inform the developers of the GDL on a range of related issues.

\subsection{Organising and managing Digital Scotland}

A number of the projects in progress at the CDLR are involved in organising and managing electronic resources that contribute towards Digital Scotland.

\subsubsection{CAIRNS}

CAIRNS (Cooperative Academic Information Retrieval Network for Scotland) is a Scotland-wide project to develop a distributed Scottish union catalogue based on the Z39.50 protocol and incorporating a mechanism to generate dynamically subsets of the total catalogue based on collection strength in particular subject areas, regional groupings (such as the GDL), and other data held in the Research Collections Online (RCO) database at its heart. It is one of the 'clumps' projects funded by the UK's Electronic Libraries Programme (for a list of eLib projects generally see their site at http://www.ukoln.ac.uk/services/elib/projects/), and is based at the

universities of Glasgow and Strathclyde, and due to end in December 2000. At the time of writing (September 2000), it has already met its key aims. A working distributed union catalogue for Scottish higher education is in place (see http://cairns.lib.strath.ac.uk/), allowing a combination of hardcopy and electronic services to be cross searched through a common user interface and returning valid circulation and holdings data as appropriate. The project also has a working 'dynamic clumper' in place, allowing users to search the RCO collection descriptions database by subject and generate a sub-clump of catalogues covering collections particularly strong in the subject area entered. Further work remains to be done, but sufficient progress has been made to enable a limited but useful service to be offered and an exit strategy prepared. This envisages ongoing maintenance of this 'limited but useful service' until at least 2004 by the CDLR and further funded development work with a view to:

- implementing a full Scotland-wide, digital and non-digital, cross-sectoral and cross domain, user configurable and adaptive resource

discovery service, together with an associated organisational collections management support service and gateway;

- implementing short-term and long-term mechanisms for dealing with metadata based interoperability problems (including retroconversion requirements);

- tackling access and authentication issues and the requirements of integrating the new extended user and staff support services and associated interfaces both with local systems, OPACs and websites, and cross-sectoral and cross domain regional groupings such as the Ayrshire Libraries Forum, and the Glasgow Digital Library. CAIRNS is one of a group of national projects with CDLR involvement. The others are described in the following sub-section and the five share a common vision of a coherent, co-ordinated and organised virtual Scotland that entails: 
- sharing resources across Scotland and providing for user access, partly through a distributed union catalogue based on Z39.50 and MARC and partly through library inter-access policies;

- managing and preserving collections collaboratively in Scotland and coordinating this effort through the use of the RCO collection descriptions database;

- linking user navigation and direction within these shared collections to collaborative collection management efforts by providing a mechanism ('dynamic clumping') that generates appropriate 'user landscapes' within the distributed catalogue based on user input.

This common vision is important to the development of the GDL because it recognises the importance of regional groupings like the GDL to cross-sectoral and cross-domain collaboration in Scotland and aims to provide mechanisms both to support collaborative collection management and user resource discovery at regional level and to integrate regional efforts into the national whole that is (or will be) virtual Scotland. CAIRNS itself is important to the development of the GDL because it is likely that the GDL catalogue will ultimately be distributed and so based on CAIRNS technologies and expertise. The project is also - along with ALF (Ayrshire Libraries Forum), SESLIN (South East Scotland Library Information Network), the GDL itself, and the SCONE project - a founder member of COSMIC, the Confederation of Scottish Mini-Clumps, an organisation that will seek to promote co-operative activity between similar cross-sectoral regional organisations across Scotland. One aim will be to investigate the use of the CAIRNS system to generate virtual gateways to the distributed catalogues of these organisations. Another will be to look at the potential for using the national approach to collaborative collection management being promoted within SCONE to perform the same co-ordinating function at a regional level.

\subsubsection{SCONE, SEED, SPIS and HILT}

Some funded work on the expansion of the coverage of the current CAIRNS service will occur through the combined work of the RSLP-funded SCONE project and the SEED project funded by the Scottish Executive Education Department, projects due to end in December 2001. SCONE is a Scotland-wide project and has a number of deliverables, the most significant of which are:

- expanding RCO and dynamic clumping (for example, including the new universities, datasets, electronic teaching and research materials created by university staff, and a range of other things);

- alternative methods of measuring collection strength (the current data is based on use of an adapted Conspectus methodology);

- providing tools to support collaborative collection development;

- mapping the RCO Conspectus subject scheme to other subject schemes (it is recognised that this subject scheme is not widely acceptable in the UK - a serious obstacle to cross-searching by subject both within Scotland and beyond it).

SEED's contribution is an examination of the feasibility of including important public library collections in the database, thereby widening the cross-sectoral scope of the clump. Both projects recognise and aim to develop the strong links that must exist between collaborative collection development between libraries and user navigation in the associated distributed catalogue environment, with the focus of this being the RCO database at the heart of both CAIRNS and SCONE and SEED. Since the GDL is a cross-sectoral grouping, currently including further education colleges and the public library as well as universities, the efforts of SEED to encompass public library collections in the RCO database will be of value to its collaborative collection management efforts. 
SPIS (Shared Preservation in Scotland) is a Scotland-wide project focusing on a shared approach to preservation of both hard-copy and electronic resources. It is based at Heriot Watt University in Edinburgh and the National Library of Scotland but the CDLR is an active participant in the management of the project and also hosts the website. It has close relationships with SCONE and SEED and will help inform the GDL about the issues of managing the preservation of digital collections in Glasgow. It is likely to draw on CAIRNS and SCONE technologies to help meet its aims.

HILT (High Level Thesaurus) is an RSLP and JISC funded study that aims to determine how the user requirement for subject cross-searching and browsing can best be met in a distributed networked environment, when the various communities, services and initiatives who have the need (higher education, further education, public libraries, museums, the archives community, the National Grid for Learning, Scotland (NGfL), the Scottish University for Industry (SufI), the Resource Discovery Network (RDN), the Distributed National Electronic Resource (DNER), the Clumps projects, and others) sometimes have different requirements, take different approaches, and, more often than not, use different subject schemes. Since this is a problem both in Digital Scotland and the Glasgow Digital Library the project is likely to play a vital part not only in their development but also their integration. HILT arose out of SCONE's research into the problems of mapping the Conspectus subject scheme used in the RCO collections database to other subject schemes in use in the Scotland, the UK generally, and elsewhere. 3

\subsection{Building Digital Scotland}

The remaining initiatives based at the CDLR focus more on building Digital Scotland - in the sense of adding one or more resources to the landscape - rather than organising it. Aside from the GDL, which will ultimately have a major role to play in this respect, current projects in this category are SAPIENS and BUBL.

\subsubsection{SAPIENS}

SAPIENS is an initiative which aims to digitise journals published by small learned societies in Scotland. As a country-wide resource, the dataset will - if present plans are implemented - be based at the CDLR rather than within the GDL. However, as a potentially significant resource held in Glasgow, it will be described in the GDL catalogue and in that sense form part of its collection. The project should also teach useful lessons about digitising resources and managing, describing and delivering digital collections that will be of value in the GDL.

\subsubsection{The BUBL Information Service}

Established in 1990 and managed by Strathclyde University since 1991, BUBL is an Internet-based information service with users in over 170 countries worldwide and also offers a specialist service to librarians and information specialists. Its major services are the BUBL Link/5:15 internet resource catalogue; BUBL Journals; BUBL UK; BUBL News; BUBL Search; BUBL Mail; BUBL Internet archive; and Acqlink and is already an important resource in the Digital Scotland landscape. Although it has no direct link as yet to the GDL, BUBL's experience and expertise in the provision of a similar service is likely to be invaluable as the GDL service develops.

\section{The GDL now: progress and plans}

Although the initial work on the GDL began in August 1999, the GDL project manager and librarian did not take up post until late January 2000. At the time of writing, therefore, the real work of the project has been underway for only a short time. Although the central aim is the creation of a distributed regional 
resource by identifying resources for digitisation, encouraging electronic content creation, cutting costs by negotiating city-wide licences, mirroring heavily used and professionally selected Internet content, identifying and setting and implementing standards, a significant part of the early work of the project has inevitably and sensibly focused on creating a sound basis for developments in these areas - an infrastructure for development and maintenance of a joint digital library that will - it is hoped - continue to function when the initial RSLP-funded project has ended at the end of 2001. The following is a summary of progress to date and immediate future plans:

A project, as opposed to service, website has been set up at http://gdl.cdlr.strath.ac.uk. This currently holds project documentation and progress reports and plans, together with contact details for the GDL Librarian, Jane Barton, and for the project management and steering groups. A service website is planned, but it is expected that earlier implementations of aspects of the service will be hosted on the project website (see below).

Local Implementation Groups have been set up for the three universities, the public library and the Glasgow Tele-colleges Network and have begun to identify and discuss issues (as have the Project Management Group and the Steering Group).

A GDL Awareness day has been held to inform staff of participating institutions about the project, encourage participation and, above all, obtain a wider set of perspectives on project issues. Following a presentation by the GDL Librarian, breakout sessions were held and a number of actions agreed, including the setting up of a GDL discussion list for staff of participating libraries, and interinstitutional task groups charged with discussing and developing the GDL in two areas: the creation and implementation of a GDL Collection Management Policy and the creation and implementation of a joint approach to web-based reference services.

The task group to develop a shared approach to web-based reference services has met several times and has now submitted a set of resources covering generally useful information about Glasgow likely to be of value to all users of the participating institutions. This material - the first of many areas of joint action on web-based reference tools - will initially be mounted on the project website and will replace separate institutional pages covering the same area of interest.

The task group on a joint collections policy has also met several times and has begun to map out the elements of a Glasgow Digital Library Collection Management Policy, covering all of the main areas of proposed content: digitisation of significant local collections, electronic teaching and research resources created in participating institutions, the negotiation of city-wide licences, and the mirroring of material identified as heavily used or as a valuable and useful addition to the collection. It is intended that this group will work closely with the SCONE project to identify or develop useful web-based tools to support acquisitions and serials librarians in managing the proposed joint collections.

Work has begun on developing the content of the library in all four of the areas identified for action:

- discussions have taken place with one supplier on city-wide licensing. Although these initial discussions are seen as being important as much for what they will teach about the conditions in which city-wide licences will be sensible, the early indications are that possibilities exist in this area attractive to both the supplier 
and the GDL libraries and that a specific proposal may emerge from these discussions;

- work has begun on the identification of heavily used content for mirroring, although early attempts to identify such content through the examination of logs from local caches have so far identified problems rather than solutions and the professional selection of resources likely to be of value to GDL users may prove a more fruitful approach in the initial stages. It is, in any case, assumed that content for mirroring will arise from an interaction between the examination of logs to identify heavily used material and proactive work by librarians and academic staff to identify useful resources and make users aware of them. Each is a valid part of collection development activity in this area. There may also be other considerations, such as whether or not improved access to the content of a resource or group of resources through, for example, full-text searching is possible and valuable, whether mirroring by the UK mirror service is sufficient to meet GDL needs in some cases, whether a resource is of sufficient physical size to make mirroring worth while, and whether the resource creator or maintainer will permit mirroring. This is a new area and may in time

require detailed examination by the collections task group with a

view to formulating a comprehensive policy;

- as has been indicated above, Strathclyde University has set up a

Digital Information Office to identify, catalogue, and maintain locally-authored electronic teaching and research resources and

encourage their creation. Its activities are still at an early stage but

work on the identification of local Strathclyde resources has begun

and discussions with the library cataloguing division have taken

place on the creation of associated metadata. The DIO will also work with other institutions to encourage similar approaches at other participating sites;

- major digitisation projects are expensive to fund. The aim in this area is partly to stimulate some level of ongoing digitisation activity in the institutions themselves but mainly to obtain significant funding for major digitisation efforts. A number of low-level bids have been submitted to SCRAN with the aim of creating small illustrative collections of digitised resources that will begin to populate the joint digital library, and will be useful resources in their own right, but whose main function will be to help support major bids to develop the resource illustrated, a good example being the proposal to create a joint illustrative collections covering the 'Red Clydeside' topic. A joint New Opportunities Fund (http://www.nof.org.uk/) bid has also been submitted.

There have also been developments in a number of other areas, including:

- early work on questions relating to how local websites and web compatible catalogues will interface with or function to comprise the

Glasgow Digital Library service interface;

- discussions on an integrated distributed catalogue of GDL resources based on CAIRNS technologies, and on the integration of this regional catalogue with CAIRNS and, hence, with Digital Scotland generally;

- a plan for regular meetings of chief librarians to discuss the possibilities for jointly funding the purchase of digital materials for the GDL;

- a sketch of the proposals for evaluating the management structures of the GDL once they have been set up. The early assumption was that the project groups, including the local implementation groups would provide the outline structure, but new elements have begun to evolve (e.g., the collections group) and it is now assumed that a fully formed evaluation plan will not be possible until a clear - if embryonic - management structure has emerged.

The Glasgow Digital Library, in conjunction with CAIRNS and SCONE and other regional co-operatives such as the Ayrshire Libraries Forum (ALF) and the South 
East Scotland Library Information Network (SESLIN), has agreed to form COSMIC, the Confederation of Scottish Mini-Clumps, currently viewed within CAIRNS and SCONE as a key organisation in the co-ordination of local, regional and national efforts to build a devolved (but coherent and co-ordinated) crosssectoral and cross-domain approach to the creation, organisation, maintenance and future development of a structured virtual Scotland - an approach which recognises the importance of regional co-operatives like the Glasgow Digital Library in linking the local with the national in virtual Scotland, both in respect of building digital content and a coherent retrieval structure, and in respect of coordinating the professional activities of staff at all levels, an aspect of building and maintaining local, regional and national virtual (and non-virtual) collections that is at least as important as other key factors such as networking infrastructure,

technical compatibility, metadata standards, and a national information policy.4

\section{Managing the solutions: co-operation is not easy}

Managing co-operation is difficult at the best of times and made more difficult by the growing ambition to act cross-sectorally. The solutions can perhaps be divided into three areas. Firstly there is the management of things. This happens of course at a technical level, but almost more importantly there is the political dimension. Resources have not only to be available, but in a distributed environment they have to be available to all irrespective of location or affiliation. This is perhaps easiest with locally owned resources as opposed to commercially purchased ones. But even with locally owned resources, the habit of sharing has to be made normal rather than exceptional. Resources have to be made coherent so that they are easily and consistently usable irrespective of their origin.

Allied to this is the second need, to manage relationships. There is a need to build trust between different parties, so that they are comfortable that other organisations (again particularly in different sectors) will behave responsibly and equitably. Here there is an initial and substantial advantage in that the country is both small enough for groups to meet and already has in the Scottish Library and Information Council a forum where librarians are used to working together.

Finally there is a need to be seen as relevant. Digital Scotland is a banner which has attracted many community groups and commercial interests. It will not be self-evident to the Scottish Executive that libraries are a major stakeholder. The case has to be made and repeated that libraries have much to offer in vision, in solutions and in best practice. Fortunately, as this article has attempted to demonstrate, the case is not difficult to make and the Glasgow Digital Library is symbolic of that.

\section{References}

1. Dennis Nicholson, Mary Steele, Gordon Dunsire and Fred Guy. Cataloguing the Internet: CATRIONA feasibility study report to the British Library Research and Development Department. London: British Library Research and Development Department, 1995.

2. D. Nicholson, University management of locally-created electronic resources: the CATRIONA II project. The Electronic Library, vol.17, no.4, August 1999, pp.247-255.

3. Ann E. Wade, Conspectus: a reappraisal. Issues in Focus, no.6, December 1 992. (http://bubl.ac.uk/org/scurl/docs/wade1.htm).

4. Derek Law, Information policy for a new millennium. Library Review, vol.49, no.7, 2000, pp.322-330. 